\title{
GUERRA ÀS DROGAS E MILITARIZAÇÃO DA SEGURANÇA PÚBLICA: DA REDEMOCRATIZAÇÃO ÀS UPPS ${ }^{1}$
}

\author{
Ana Clara Telles C. de Souza ${ }^{2}$
}

Gabriel Gama de O. Brasilino ${ }^{3}$

\begin{abstract}
Resumo
O presente artigo busca olhar para as heranças da ditadura civil-militar no Brasil a partir de uma análise sobre a relação entre "guerra às drogas" e a militarização da segurança pública nos contextos brasileiro e latino-americano. Lidando especificamente com o caso do Rio de Janeiro, argumenta-se, em primeiro lugar, que é legado da ditadura brasileira olhar para a segurança pública sobre o ponto de vista militarizado da lógica do "inimigo"; e que essa lógica se alimenta no contexto latinoamericano da "guerra às drogas" e do "combate" e "eliminação" do tráfico ilícito. Procurou-se fazer uma revisão das bibliografias sobre militarismo e militarização, transição democrática, estudos críticos sobre drogas ilícitas e (in)segurança internacional a fim de oferecer uma leitura multifacetada sobre o objeto de estudo proposto. Por fim, concluiu-se que, para além de debater o futuro das Forças Armadas em regimes recém-democráticos, é preciso abordar a militarização da função policial no contexto urbano de "guerra às drogas" e de globalização da guerra como configuração de biopoder relacionado à governança econômico-política neoliberal e à política internacional antidrogas.
\end{abstract}

Palavras-chave: Guerra às Drogas. Militarização. Segurança Pública. Ditaduras Civis-Militares; Biopoder.

\begin{abstract}
This article aims at looking to the heritages of the civil-military dictatorship Brazil through an analysis of the relations between the "war on drugs" and the militarization of public security in the Brazilian and Latin American contexts. Dealing specifically with the case of Rio de Janeiro, it argues, firstly, that looking to public security through a militarized lens of the "enemy" is a legacy of the Brazilian dictatorship; and that such logic is fed, in the Latin American context, by the "war on drugs" against illicit drug trafficking. A review of the literatures on militarism and militarization, democratic transition, critical drug studies and international (in)security was offered in order to provide a multifaceted reading on the proposed object of study. Ultimately, the article concludes that, beyond the future of the Military in recent democratic regimes, it is necessary to address the militarization of the police function in urban contexts of the "war on drugs" and the globalization of war as biopower, related both to neoliberal governance and to the international antidrug politics.
\end{abstract}

Keywords: War On Drugs. Militarization. Public Security. Civil-Military Dictatorships. Biopower.

\section{Resumen}

Este artículo busca mirar la herencia de la dictadura civil-militar en Brasil apartir de un análisis sobre la relación entre la "guerra contra las drogas" y la militarización de la seguridad pública en los contextos brasileño y latinoamericano. Tomando especificamente el caso de Rio de Janeiro, se argumenta, en primer lugar, que, observar la seguridad pública desde un punto de vista militarizado de la lógica do "inimigo" es un legado de la dictadura brasileña; y que esa lógica se alimenta en el contexto latinoamericano de la "guerra conntra las drogas" y del "combate" y "eliminación" del tráfico ilícito. Se busca hacer una revisión de las bibliografias sobre militarismo y militarización, transición democrática, estúdios críticos sobre drogas ilícitas e (in)seguridad internacional con el fin de ofrecer una lectura multifacetada acerca del objeto propuesto. Finalmente, se conclue que, más

\footnotetext{
${ }^{1}$ DOI deste artigo: $10.5380 /$ recp.v6i2.42550.

2 Doutoranda do Instituto de Relações Internacionais da Pontifícia Universidade Católica do Rio de Janeiro. E-mail: anaclara.telles@hotmail.com.

${ }^{3}$ Estudante do último ano da graduação em Relações Internacionais da Pontifícia Universidade Católica do Rio de Janeiro. E-mail: gabrielgob1@hotmail.com.
} 
allá de debatir el futuro de las Fuerzas Armadas en regímenes recién democráticos, es necesario abordar la militarización de las funciones policiales en el contexto urbano de la "guerra contra las drogas" y de la globalización de la guerra como configuración de biopoder, relacionado a la governanza económico-política neoliberal y a la política internacional antidrogas.

Palabras-clave: Guerra Contra Las Drogas. Militarización. Seguridad Pública. Dictaduras CivilMilitares. Biopoder.

\section{INTRODUÇÃO}

O “novo” modelo de segurança pública do Rio de Janeiro, orientado por critérios de "policiamento comunitário", tem como expoente mais recente as chamadas Unidades de Polícia Pacificadora (UPPs). Se, por um lado, as UPPs dão novo fôlego à trajetória de popularização do conceito de "policiamento comunitário" dentre as polícias militares brasileiras, que começa ainda na década de 1990 como processo de reforma organizacional pautado pela descentralização das tomadas de decisão e da colaboração com a comunidade, por outro, reconfiguram conceito de policiamento junto às chamadas "áreas subnormais" (ou favelas) da cidade do Rio de Janeiro, onde a recuperação da soberania via ocupação militar se torna atividade motriz (RIBEIRO \& MONTANDON, 2013). Incluindo forças policiais civis e militares, Polícia Federal, Exército, Fuzileiros Navais, tanques, metralhadoras e fuzis, o projeto das UPPs se caracteriza por fortes práticas militarizadas de cunho discursivo e não discursivo, a começar pelo uso de expressões como "conquista territorial", "ocupação estratégica" e "pacificação" até o hasteamento da bandeira nacional em clara alusão à “conquista do território inimigo" (RODRIGUES, 2012; KARAM, 2013, p. 2).

No imaginário das UPPs, recupera-se o monopólio estatal do uso legítimo da força em comunidades e favelas em que se supunha haver domínio anterior de atores paramilitares não estatais envolvidos com o "tráfico de drogas". A uma retórica militarizada sobre esses espaços conjuga-se um conjunto de suposições sobre o "inimigo" a ser combatido relacionado, grosso modo, ao modelo punitivo através do qual se configurou, internacionalmente, o regime de controle de drogas ilícitas, fundamentado na proibição global à produção, ao comércio e ao consumo de determinadas substâncias psicoativas. Como argumenta Thiago Rodrigues, é imprescindível conhecer a história política do regime internacional de drogas e sua orientação repressiva "que, em termos geopolíticos e no plano global, foram traduzidos no apoio à militarização do combate ao narcotráfico" se quisermos compreender mais amplamente o contexto latino-americano da segurança pública e as relações civis-militares no continente (RODRIGUES, 2012, p. 35). Nesse sentido, as UPPs reconfiguram, através de um arcabouço militarizado para lidar com questões políticas como 
a criminalidade, a violência urbana e as desigualdades sociais, a lógica da "guerra às drogas" latino-americana, que localiza no "tráfico de drogas" a principal ameaça à paz e à segurança da região.

O presente artigo busca olhar para as heranças das ditaduras civis-militares na América Latina a partir de uma análise sobre a relação entre "guerra às drogas" e a militarização da segurança pública no Brasil. Lidando especificamente com o caso do Rio de Janeiro, argumenta-se, em primeiro lugar, que é legado da ditadura brasileira olhar para a segurança pública sobre o ponto de vista militarizado da lógica do "inimigo"; e que essa lógica se alimenta, no contexto latino-americano, da "guerra às drogas", em que estratégias para coibir o comércio internacional de drogas ilícitas se materializam em uma abordagem militarizada de "combate" e "eliminação" de ameaças. No caso dos espaços periféricos do Rio de Janeiro, alvos prioritários das políticas de ocupação "pacificadora", para além da restruturação da autoridade estatal através da militarização da segurança pública, intensificam-se fenômenos como a criminalização da pobreza e a institucionalização do racismo, também em função de uma política antidrogas de alcance global.

Ao analisar a relação entre "guerra às drogas" e a militarização da segurança pública no Brasil pós-redemocratização, o artigo também pretende desestabilizar suposições enraizadas sobre o papel do militarismo nas sociedades democráticas contemporâneas, sobre as relações civis-militares no continente latino-americano e sobre as relações históricas entre as Forças Armadas e as instituições policiais. Em específico, busca-se problematizar a naturalização corrente que se faz da distinção entre o que são relações sociais de cunho "civil" e de cunho "militar", onde termina a "guerra" e onde começa a "paz" e quais são as funções "militares" e as funções "policiais". Entendendo o militarismo como o fenômeno de penetração nas relações sociais de discursos, saberes e práticas militares, e a militarização como seu processo de expansão (SHAW, 2013), concretiza-se uma ruptura com leituras sobre transição democrática centralizadas na figura institucional das Forças Armadas ou que avancem um entendimento estadocêntrico da relação entre política, militarismo e militarização.

Começaremos nossa análise pela recuperação de parte da literatura sobre militarismo, regimes democráticos e relações civis-militares, com olhar especial para o que é produzido sobre a América Latina. Em seguida, será brevemente abordada a bibliografia sobre militarismo e transição democrática no Brasil, buscando leituras críticas sobre segurança 
pública no Brasil pós-redemocratização. Na quarta parte, serão apresentados, com mais profundidade, algumas das leituras contemporâneas sobre militarização da segurança pública e "guerra às drogas" no Brasil e na América Latina, procurando dialogar com o que foi exposto nas seções anteriores do artigo. Por fim, uma breve conclusão dará conta dos debates atuais sobre o tema nos contextos brasileiro, latino-americano e global com vistas a situar o presente trabalho nas discussões contemporâneas sobre políticas globais antidrogas e militarização da segurança pública.

\section{MILITARIZAÇÃO, MILITARISMO E PRETORIANISMO NOS DEBATES SOBRE DEMOCRATIZAÇÃO}

Em Democratic Militarism: Voting, Wealth and War (2014), o acadêmico estadunidense Jonathan D. Caverley busca explicar a existência da agressividade militar em democracias bem consolidadas através de variáveis como a influência da opinião pública e o papel das elites políticas e econômicas na definição da política externa. Utilizando-se de um conceito bem definido de militarismo, o autor o entende como "a condition in which a large portion of society supports the building of an excessively strong military, believe in its superior efficacy as a foreign policy tool, and exhibits a heightened willingness to use it" (CAVERLEY, 2014, p. 3). Também de acordo com essa conceituação, o militarismo seria confinado a uma área específica das relações sociais - a política internacional, ou externa -, dizendo unicamente respeito à forma como Estados nacionais se relacionam com seus pares no "plano internacional". Uma das principais conclusões a que Jonathan D. Caverley chega é a de que a influência da opinião pública é mais importante para o envolvimento de democracias bem estabelecidas em investidas militares do que a atuação das elites estatais.

A leitura de Caverley sobre militarismo se situa em um contexto mais amplo de produção bibliográfica sobre militarismo e regimes políticos democráticos que se mostra relativamente profícua durante o século XX. Preocupada em desvendar esquemas explicativos gerais, essa bibliografia dedica pouca atenção a fatores históricos e contingentes em favor de variáveis - seja em nível estrutural ou unitário - que possam ser calculadas objetiva e cientificamente. Por se pretender universal, essa literatura apaga tentativas de historicizar o fenômeno do militarismo, tomando-os como independentes de contextos histórico e politicamente variados. Além disso, a despeito de sua tentativa de olhar para a relação entre militarismo e sociedade, acaba reproduzindo uma visão única sobre o papel político das Forças Armadas, nomeadamente, como agente estatal exclusivamente de política 
externa. Nesse sentido, é precisamente o tipo de conceituação que desenha fronteiras em vez de buscar desconstruí-las.

Uma tentativa mais abrangente de construir uma teoria geral sobre democratização a partir de fatores específicos como o militarismo e as Forças Armadas vem de Larry J. Diamond et al. em Democracy in Developing Countries: Latin America (1999). Já na introdução à análise proposta, os autores apresentam o militarismo como uma importante variável a ser considerada em teorizações sobre o futuro da democracia em países em desenvolvimento, nomeadamente na América Latina. Os autores são enfáticos ao afirmar que tentarão não reproduzir dois dos equívocos mais comuns quando se analisa o papel das Forças Armadas em regimes políticos: acreditar que o militarismo é apenas um anacronismo cultural que será abandonado naturalmente com o advento da democracia; e se utilizar do determinismo funcionalista que vê nos militares apenas um instrumento das elites e oligarquias que expressa, portanto, fatores socioeconômicos exógenos.

Dito isso, a leitura apresentada por esses autores é interessante porque deixa espaço para se pensar o militarismo e a militarização nas democracias emergentes a partir de um recorte histórico e, ao mesmo tempo, contextualizado ao ambiente latino-americano. Nesse caminho, os autores apontam diferentes fatores a serem levados em consideração ao se estudar comparativamente alguns dos países da América Latina, como o papel histórico das Forças Armadas, as características da cultura militar subjacente a elas e até mesmo a configuração orçamentária dos Estados recém redemocratizados. É interessante, ainda, a parte em que comentam sobre o papel que se reserva aos militares no século XXI, sobretudo no que tange a novos desafios de segurança interna e internacional:

The incapacity of democratic regimes to deal successfully with widespread violence, guerrilla warfare, urban terrorism, and other forms of violence makes the military a much more relevant political actor than it is in more pacified and stable societies. As Stepan has shown, once the expansion of institutional mission and prerogatives occurs, it tends to endure and advance, diminishing not only the stability but also the authenticity of democracy, as numerous areas of public policy pass from elected civilian to unaccountable military control. It is thus imperative that newly restored democracies in Latin America (and elsewhere) reorient the military role around external defense, reduce military prerogatives to control or influence vast reaches (military and nonmilitary) of the state, the political system, and even civil society, and assert civilian control and oversight even over strictly military functions (DIAMOND et al., 1999, p. 34). 
Diamond et al. veem no processo de militarização das políticas públicas um potencial fator de ameaça à democracia na América Latina. Segundo os autores, uma solução permanente para esse dilema seria capacitar uma força policial de controle civil de forma que seja possível prescindir das Forças Armadas ao lidar com conflitos internos. De forma parecida, Kirk S. Bowman, em Militarization, Democracy and Development (2004), também argumenta que a militarização, um fenômeno corrente na América Latina, tem efeitos substancialmente negativos no desenvolvimento político e econômico da região, contradizendo as leituras convencionais que argumentam ser a militarização benéfica para a modernização de países em desenvolvimento. Utilizando-se da análise histórica sobre dois estudos de caso - mais precisamente, Honduras e Costa Rica -, Bowman também discute o papel direto e decisivo dos Estados Unidos na intensificação de processos de militarização na região, cujos impactos negativos na estabilidade da democracia latino-americana são evidentes, sobretudo, durante o período da Guerra Fria. Sobre isso, o autor coloca um importante questionamento:

But now the Cold War is over. Communism is no longer a threat. The Left has largely abandoned the armed struggle. Most countries of Latin America are formal democracies and formal democracies are not supposed to engage in wars with each other. [...] The end of the military as an arbiter of power has arrived! Or has it? Nunn (1995) has demonstrated that the thinking of the generals has not changed with the times. They still see enemies around every corner and see themselves as the guardian of the Patria. And in spite of the conventional wisdom that 1989 marked the demise of communism and the reduction of military budgets, the U.S. Arms Control and Defense Agency reveals a disturbing pattern in South American military budgets (BOWMAN, 2004, p. 250).

Os trabalhos de Diamond et al. (1999) e de Bowman (2004) nos parecem essencial como introdução para a discussão que queremos avançar na próxima seção. À parte da literatura tradicional sobre democracia na América Latina que herda da teoria da modernização - e também de seus críticos - um maneirismo metodológico economicista e que busca mecanismos gerais de explicação, existe uma literatura crescente que, a partir de análises históricas e de reflexões políticas, discute a consolidação da democracia em meio a um crescente processo de militarização na região. De forma a nos aprofundarmos nesse tema, escolhemos discutir o caso brasileiro a partir de leituras sobre políticas militarizadas no período pós-redemocratização, com foco na articulação da militarização da segurança pública à retórica internacional de "guerra às drogas". 


\section{DEMOCRATIZAÇÃO, MILITARIZAÇÃO E SEGURANÇA PÚBLICA NO BRASIL}

De acordo com Alfred Stepan (1988), uma das principais questões enfrentadas em processos de transição entre um regime autoritário militar e a democracia diz respeito à capacidade do novo governo civil de controlar as Forças Armadas. Segundo o autor, nesse momento, há duas dimensões particularmente importantes a serem avaliadas pelo novo regime: a possível contestação militar articulada contra políticas do novo governo; e as prerrogativas militares institucionais a serem atribuídas (ou conservadas) às Forças Armadas. No esquema proposto por Stepan, quanto menor for a incidência de ambas as dimensões no novo regime democrático, maior será a probabilidade de controle civil efetivo da elite militar.

Segundo Jorge Zaverucha (2008), no caso brasileiro, o ímpeto de garantir apoio militar ao regime democrático recém-instaurado levou os líderes do governo a fazer importantes concessões às Forças Armadas, conservando instituições autoritárias como preço pela negociação. Para o autor, no entanto, longe de transitórias e passageiras, essas concessões se aprofundaram nas décadas seguintes à redemocratização. Dessa forma, em contraste com posições otimistas sobre o período de transição democrática no Brasil - expressadas por autores como Wendy Hunter (1997), Ronaldo Costa Couto (1998) e José Murilo de Carvalho (1999), que celebravam o retorno dos militares aos quartéis -, Zaverucha argumenta que o que se vê com cada vez mais intensidade é a militarização da política brasileira, especialmente no que se refere ao âmbito das políticas públicas.

Sobre o período de transição democrática brasileira, Stepan (1988) aponta como aspecto facilitador o fato de que, tanto nos últimos anos de regime militar quanto nos primeiros anos que se seguiram à redemocratização, o percentual do Produto Interno Bruto (PIB) destinado aos gastos militares era relativamente baixo, especialmente se comparado a outros países latino-americanos como Argentina e Uruguai, mas estável. De acordo com o autor, esse quadro apaziguava os interesses da nova elite política democrática - que não tinha motivos para disputar uma parcela do orçamento militar - e também dos atores militares, que garantiam a manutenção da verba destinada às Forças Armadas. Uma década depois, no entanto, Zaverucha (2001a) salientava um aumento expressivo dos gastos orçamentários de cunho militar (acompanhado do aumento também significativo da tropa brasileira) em relação a 1985, acompanhando tendência vista em países como Colômbia e Venezuela - que estavam, respectivamente, em guerra civil e em litígio fronteiriço. 
É interessante notar que, indo de encontro à tendência latino-americana de desmilitarização da política - verificada entre os argentinos, uruguaios e chilenos -, o Brasil parece se submeter por um processo de crescente adoção de conceitos, doutrinas e procedimentos militares em atividades de natureza civil (ZAVERUCHA, 2011b). Para Zaverucha (2005 apud SOUZA, 2013), esse fenômeno se materializa em um duplo movimento de policialização das Forças Armadas, por um lado, e de militarização das polícias, por outro. Em outras palavras, o que o acadêmico parece observar é que, enquanto se atribuem cada vez mais funções de polícia - ostensivas e investigativas - a instituições militares de defesa, intensifica-se também a caracterização das forças policiais a partir de referenciais militares, uma herança política do período autoritário militar.

Em relação ao fenômeno de militarização das polícias, não há exemplo mais paradigmático no Brasil do que a própria existência das polícias militares. Embora suas origens oficiais remontem ao início do século XIX, é durante o regime militar instaurado em 1964 que essas instituições ganham prerrogativas de polícia ostensiva, responsáveis por garantir no território a lei e a ordem e antes atribuídas à Polícia Civil (ZAVERUCHA, 2000). Dada a incapacidade das forças policiais civis de exercerem as tarefas de controle exigidas pelo regime militar, são estendidas as prerrogativas das polícias militares para além da função de força auxiliar das unidades federativas (PINHEIRO, 1982).

Vinda a redemocratização, o que ocorre, segundo o diplomata e acadêmico Paulo Sérgio Pinheiro (1982), é uma continuidade entre a lógica do combate à subversão e a guerra contra o crime. Ao confundir a repressão política e a repressão comum, coloca-se em curso, segundo o autor, uma concepção específica do Estado e da sociedade, uma em que a lógica militar pode transpor o ofício policial sem grandes obstáculos, concretizando-se no combate aos "inimigos internos" em vez de a ameaças exteriores. Promulgada a Constituição Federal de 1988, reforça-se a centralidade das polícias militares na seara da segurança pública, tornando ainda mais turva a linha que separa a vocação militar de defesa da soberania nacional e a função policial de ordenamento social interno - condição sine qua non para qualquer regime democrático (ZAVERUCHA, 2008).

Não à toa é tratada com naturalidade a subordinação das forças policiais militares às Forças Armadas nacionais, materializando uma dubiedade em relação às funções de ambas as instituições. Nesse processo, torna-se ainda mais evidente a forma como os movimentos de militarização da polícia e de policialização das Forças Armadas se confundem, de forma que militarizar o policiamento ostensivo é também dar prerrogativas de decisão aos militares 
sobre questões de segurança pública. As forças policiais militares passam a ser usadas, portanto, para conter ameaças políticas e sociais à ordem a partir da lógica militarista do “inimigo”, dessa vez interno (ZAVERUCHA, 2001b).

Nas palavras de Zaverucha:

En Brasil, como resultado de una transición pactada, la democracia electoral convive con enclaves autoritarios fuertemente enquistados en el aparato estatal. Esta situación, lejos de resolverse, se ha profundizado en los últimos años debido al incremento de la violencia urbana y la creciente militarización de las operaciones destinadas a garantizar la seguridad pública. La confusa situación institucional de la Policía Militar y el rol cada vez más importante del Ejército demuestran que, a diferencia de lo que ocurre en los países desarrollados, en Brasil las funciones de defensa nacional se entremezclan peligrosamente con la de mantenimiento del orden interno. El resultado es un híbrido institucional que impide la construcción de una democracia plena (ZAVERUCHA, 2008, p. 128).

Se, por um lado, o Exército ganha cada vez mais prerrogativas sobre as polícias militares estaduais - Zaverucha (2008) chega a dizer que essas instituições, atualmente, respondem a dois patrões diferentes -, por outro, proliferam-se militares em ativa ou em reserva em posições civis da administração governamental, seja em âmbito estadual ou nacional (ZAVERUCHA, 2000). Esse fenômeno pode ser observado, sobretudo a partir da década de 1990, no grande número de generais em reserva que já ocuparam cargos de Secretário de Segurança Pública em unidades federativas tão diversas quanto Ceará, Espírito Santo, Tocantins e Rio de Janeiro e também posições de direção em órgãos federais, como a Secretaria Nacional de Políticas sobre Drogas (SENAD), que, no início de sua história, era vinculada à Casa Militar. Ambos os processos têm como consequência a militarização das políticas públicas sobre segurança, sejam elas de cunho político - a repressão militar a manifestações populares e greves - ou social - a estratégia militarizada de "ocupação" de áreas pobres dos centros urbanos, como no caso da operação policial militar deflagrada no Complexo do Alemão, no Rio de Janeiro, em 25 de novembro de 2010, com apoio de pessoal e armamentos da Marinha do Brasil (ZAVERUCHA, 2008).

Enquanto Stepan (1988) percebe o fenômeno de proliferação de "múltiplas funções" das Forças Armadas brasileiras como um aspecto positivo para a democracia - uma vez que afastaria, segundo ele, os perigos de uma "crise de missão" por parte dos militares -, Zaverucha (2008) vê com olhos de desconfiança a difusão de lógicas e práticas militares e o envolvimento das Forças Armadas em atividades civis, sobretudo no que tange à segurança 
pública. Para o último, quando isso acontece, passa-se a falar o "idioma da guerra”, em que discursos sobre segurança alimentam a lógica da doutrina de segurança nacional para questões de políticas públicas (ZAVERUCHA, 2000 e 2008). É interessante observar, nesse ponto, como essa leitura se interseciona com uma bibliografia cada vez maior em Relações Internacionais sobre processos de securitização e militarização das políticas doméstica e internacional. Originária de correntes teóricas tão distintas como os estudos críticos, o feminismo e o pós-estruturalismo, essa bibliografia questiona as consequências políticas de se tornar determinado assunto da esfera política uma questão de segurança ou de guerra. Enquanto leituras tradicionais entendem que o ato de tornar determinada questão um assunto de segurança nacional ou internacional abre espaço para a legitimação de medidas não democráticas e a instauração de um regime de exceção - assim entende a Escola de Copenhague, por exemplo -, abordagens mais críticas veem processos de securitização e militarização como instrumento justificador de uma excepcionalidade não democrática que, na verdade, é a regra, mesmo em regimes políticos ditos democráticos (FIERKE, 2007). Outras leituras, ainda, entendem que o fenômeno de mobilização de determinadas questões dentro da seara de segurança nacional - manipulando, portanto, imagens como soberania e sobrevivência estatal - reflete percepções e concepções bastante específicas sobre o político, em que preceitos comumente identificados como democráticos são intencionalmente deixados de lado (HUYSMANS, 2006).

Sendo assim, no Brasil pós-redemocratização, o processo de militarização das políticas públicas, sobretudo aquelas direcionadas à segurança, constitui um importante obstáculo para o exercício de uma democracia plena (ZAVERUCHA, 2008). Nas palavras de Zaverucha, o que parece ocorrer é um "pretorianismo moderado", em que "los civiles pueden gobernar, pero el gobierno se encuentra bajo la supervisión de las Fuerzas Armadas en los asuntos de interés militar, como las operaciones de seguridad pública destinadas a garantizar el orden y el cumplimiento de las leyes" (ZAVERUCHA, 2008, p. 144). Segundo o autor, o conservadorismo da democracia brasileira em relação aos interesses militares faz com que as Forças Armadas sequer sintam necessidade de dar um golpe de Estado, dando a falsa impressão de que os militares estão de fato recolhidos aos quartéis e afastados dos processos de decisão (ZAVERUCHA, 2001a).

Além disso, discute-se de que forma a tradição cultural brasileira de cunho militarista exerce um papel importante nesse processo. Ainda segundo Zaverucha, no Brasil, parece existir uma cultura militar que assegura às Forças Armadas o papel de salvadora da nação e 
defensora de república, inclusive contra ameaças domésticas (ZAVERUCHA, 2008). Nesse quadro, as qualidades profissionais dos militares são contrastadas à classe política, frequentemente entendida como imatura, indisciplinada ou propensa à corrupção (ZAVERUCHA, 2000). Não à toa, a militarização da segurança pública é um processo endossado por militares e civis, por generais e políticos de esquerda e de direita, pela mídia e pela opinião pública.

Cabe observar, por fim, como essa leitura vai ao encontro do argumento de Kirk Bowman (1988) sobre pretorianismo na América Latina. Endossando o trabalho de Andreski (1954), Bowman acredita que uma das principais ameaças à democracia surge quando as Forças Armadas deixam de lado sua vocação para a defesa nacional contra inimigos externos para se voltar para o âmbito doméstico. Desde o fim da Guerra Fria, em âmbito internacional, e do ocaso dos regimes militares autoritários na região, em nível nacional, pensava-se que finalmente a ingerência militar sobre assuntos políticos internos seria substituída por um regime democrático capaz de exercer controle civil sobre as Forças Armadas. Não são poucos os acontecimentos, no entanto, que sugerem uma intensificação da militarização da política brasileira.

\section{GUERRA ÀS DROGAS E MILITARIZAÇÃO DA SEGURANÇA PÚBLICA NA AMÉRICA LATINA}

Retomando o argumento de Zaverucha (2005), no caso brasileiro, a militarização da segurança pública segue dois rumos: a ingerência das Forças Armadas, como instituição, nos assuntos de ordem doméstica e a militarização das forças policiais ostensivas e investigativas que, supõem-se, deveriam preservar orientação minimamente civil. Ademais de as instituições responsáveis pelo policiamento ostensivo serem de natureza militar, observa-se que há a difusão de uma lógica militarizada - i.e., relacionada à condução da, e preparação para a, "guerra" (STAVRIANAKIS \& SELBY, 2013, p. 3) - por todas as esferas narrativas e práticas da segurança pública no Brasil. Quando olhamos para o projeto das UPPs e para a ocupação militar das "favelas" como condução da "guerra" por excelência, esse processo se torna ainda mais evidente. É o que Maria Lúcia Karam (2013) chama de "militarização ideológica", seguindo debate antigo que já ocorria dentro e fora das instituições policiais militares pelo menos desde a década de 1990. 
Anna Stavrianakis e Jan Selby (2013) oferecem uma compreensão sociológica sobre o mesmo fenômeno, transcendendo a divisão naturalizada entre os âmbitos civil e militar para entender de que maneira o militarismo está inserido no tecido social. No livro que organizam sobre militarismo nas Relações Internacionais, Martin Shaw (2013) aborda o militarismo de forma parecida, utilizando o conceito de military para descrever todas as relações sociais, instituições e valores relacionados à preparação para e à condução da violência política organizada. Ainda de acordo com esses autores, historicamente, o militarismo era entendido como uma ideologia de glorificação da guerra, das instituições militares e da prevalência de valores marciais na sociedade. Entretanto, concepções centradas na ideologia foram se tornando raras, tanto porque guerras e militares não são mais glorificados como antes quanto porque seria reducionista essencializar o militarismo como ideologia (STAVRIANAKIS \& SELBY, 2013, p. 12). É possível problematizar, segundo essa perspectiva, a ideia de "militarização ideológica" como endossado por Karam (2013). Ainda assim, isso não quer dizer que a os agentes de (in)segurança estejam isentos de influências ideológicas.

Stavrianakis \& Selby (2013) também chamam atenção para como as transformações mais recentes na estrutura de produção e gastos militares, bem como a penetração do militarismo na cultura, ocorrem em um pano de fundo de liberalização política e econômica. Nesse sentido, "neoliberalization has led not to a waning of militarism, but instead to its rearticulation through networks and actors criss-crossing the public-private divide" (STAVRIANAKIS \& SELBY, 2013, p. 17). Nesse quadro se inserem tanto o reforço das relações entre o setor privado e o exército, ou a privatização da segurança, quanto os processos de militarização da aplicação da lei em favor do interesse neoliberal, presentes em muitos países na América Latina e no próprio contexto da "guerra às drogas".

O argumento de Stavrianakis \& Selby (2013) é construído em torno da necessidade de se chamar a atenção para a persistência de uma lógica estatal no sistema internacional. Um aspecto relevante seria como a globalização é articulada em abordagens como a das "novas guerras", de forma a subsidiar um processo de expansão da paz liberal e da biopolítica para além das fronteiras dos Estados e em nome da humanidade (JABRI, 2007). Assim, é importante entender que, por mais que a lógica estatal permeie a militar, os estudos em torno do militarismo e da militarização devem se atentar para outros níveis de análise e para a incorporação da lógica militar nas sociedades ou à possibilidade de desmilitarização. Quanto a essas preocupações, podemos dizer que o trabalho de Thiago Rodrigues (2012) também é 
de grande relevância.

Traçando uma trajetória compreensiva da militarização das políticas antidrogas em âmbito internacional e sua configuração como "guerra às drogas" na América Latina, Rodrigues (2012) se situa em uma crescente literatura sobre os processos de militarização da segurança pública, sobretudo, em países onde prolifera a associação discursiva entre drogas ilícitas e violência, como é o caso, na visão do autor, de Brasil e México. Interessantemente, Rodrigues busca problematizar não apenas os discursos repressivos de cunho proibicionista - i.e., que advogam a proibição irrestrita de determinadas substâncias psicoativas -, como também os discursos reformistas que, apesar de críticos da criminalização das drogas hoje ilícitas, preservam o caráter punitivo e de seletividade característicos das políticas globais sobre drogas, enquadrando-as em discursos humanistas e de saúde pública. Em específico, ele argumenta:

Em outros Estados, como no Brasil e no México, a "guerra às drogas" reforçou políticas de segurança pública voltadas à repressão seletiva aos grupos sociais empobrecidos (BATISTA, 2003). Em suma, a adesão por parte dos países latino-americanos não foi uma mera sujeição à agenda de segurança hemisférica estadunidense. Ao contrário, as intenç,óes dos EUA encontraram pontos de conexão em cada pás que aderiu ao proibicionismo. Os Estados latino-americanos não foram, assim, meras marionetes dos interesses geopolíticos estadunidenses traduzidos nas açôes da "guerra à drogas". Por isso, alguns deles, como a Colômbia, o México e o Brasil podem ser interessantes laboratórios de análise desse processo de adequação local ao proibicionismo militarista financiado pelos Estados Unidos (RODRIGUES, 2012, p. 23).

Outro aspecto fundamental no debate sobre "guerra às drogas" e militarização é o fato de que processos de desmilitarização em determinadas regiões podem levar à militarização em outras. Essa irregularidade ou “desnível geográfico" é entendida por Dominic Corva (2009) como a expansão do caráter biopolítico da guerra. Nas palavras do autor, "the uneven geography of state power has facilitated the transnationalization of the militarized police function, to places where its biopolitical liberalism has been, and continues to be, widely contested" (CORVA, 2009, p. 170). O autor sinaliza para a necessidade de se fazer uma análise da desigual globalização do poder soberano através da militarização da função da polícia e, em específico, do papel dos Estados Unidos nesse processo. Como ele argumenta, o governo dos Estados Unidos tem sido um nexo necessário no plano internacional para consolidar e transnacionalizar a normalização da guerra como biopoder através da função policial. Nesse quadro, as estratégias biopolíticas de governança garantem 
a reprodução de ordens sociais hegemônicas, o que implica a desigualdade geográfica no exercício dessa governança.

A militarização é entendida por Corva como "the expansion of the criminal justice apparatus to intensify unprecedentedly harsh punitive sanctions and coercive practices, with attendant collateral damage, especially in urban centers and against socioeconomically excluded populations" (2009, p. 164-65). Para além de uma visão histórico-geográfica, o autor articula uma abordagem sociológica e institucional com argumentos críticos ao processo de militarização das sociedades, algo que Thiago Rodrigues (2012) também nos convida a fazer. Nesse quadro, poderíamos dizer que o Rio de Janeiro vive um processo de expansão do aparato de justiça para intensificar práticas coercitivas e punitivas, acompanhadas de "danos colaterais" contra populações histórica e socioeconomicamente excluídas. De acordo com Corva, essa forma de reestruturar o Estado através da militarização expandiu o poder policial, o encarceramento em massa e a erosão das liberdades civis ao passo que se redimensionaram os direitos de cidadania e participação universal em espaços públicos. Em suas palavras:

The war on drugs fundamentally alters the rights and responsibilities of the most vulnerable sectors of the U.S. population by normalizing what it means to be an economically productive body in society. This biopolitical discourse, in turn, has underwritten the highly repressive practices of the national penal state (CORVA, 2009, p. 165).

Nesse contexto, Corva parte de discussão cada vez mais consolidada sobre a crescente indistinguibilidade entre a função de guerra e a função policial na era da globalização. Se antes a distinção entre as funções de polícia e exército se dava na ação sobre sujeitos dentro ou fora das fronteiras do Estado-nação, agora essa distinção está cada vez mais porosa. Exemplo claro dessa contradição na cidade do Rio de Janeiro foi a ação das forças armadas brasileiras, em parceria com a Secretaria Estadual de Segurança Pública do Estado do Rio de Janeiro, na invasão do Complexo do Alemão em 2010 para execução de um projeto de "policiamento comunitário" pautado pela retomada da soberania estatal via ocupação territorial (RODRIGUES, 2012; KARAM, 2013).

Sobre a relação entre processos de militarização das Américas, a reafirmação da soberania estatal, o uso das Forças Armadas em âmbito doméstico e as políticas internacionais sobre drogas, Rodrigues argumenta:

O amplo processo de securitização planetária do narcotráfico confunde ou interseciona os espaços de segurança doméstico e internacional. Essa sobreposição de planos de segurança propicia que discursos diplomático- 
militares proibicionistas, com os Estados Unidos à frente, justifiquem a utilização das Forças Armadas no enfrentamento ao narcotráfico, pois, simultaneamente, a soberania e a ordem interna dos Estados estariam ameaçadas (RODRIGUES, 2012 p. 34).

Corva (2009) identifica dois elementos sobre como a militarização da função policial foi transnacionalizada através da guerras às drogas. Primeiro, ela foi promovida através de instituições de governança econômica neoliberal que reproduziram vulnerabilidades no sul. Nesse sentido, "guerra às drogas" e neoliberalismo transnacional se intersecionam na atuação de agências internacionais que promovem a proibição global, seja pela via da segurança, seja pela via do desenvolvimento. Em segundo lugar, a militarização das forças policiais na América Latina e o aumento do encarceramento em massa expressam o recrudescimento da função policial contra populações historicamente excluídas na imposição da ordem. "The enemies of drug war policies are embodied as gendered, racialized, ethnic and poor people", como afirma o autor (CORVA, 2009, p. 168).

No Brasil, o quadro não é diferente. Luciana Boiteux (2015) argumenta que a lei 11.343 de 2006, conhecida à época como "nova lei de drogas", marca o reforço do endurecimento penal contra o comércio de drogas ilícitas, o que constitui um dos principais fatores do aumento da população carcerária brasileira nos últimos anos. Segundo dados oficiais de 2014 , alcançaria cerca de 30\% do total - 63\% no caso do encarceramento de mulheres (DEPEN, 2014). Em suas palavras, "poderíamos pensar que o aumento da punição teria reflexo na desarticulação das redes criminais devido ao encarceramento dos grandes traficantes, mas o que se verifica na prática é um reforço da seletividade penal, com intensificação da criminalização da pobreza” (BOITEUX, 2015, p. 142). A autora continua:

A partir do estudo de caso do Rio de Janeiro, se sabe que o perfil dos condenados por tráfico de drogas é de pessoas sem antecedentes criminais (66,4\%); detidos em flagrante (91,9\%); 65,4\% respondem somente por tráfico (art. 33, sem associação ou formação de quadrilha), e 15,8\%, com associação. Desses, 83,9\% do sexo masculino. (...) A maioria dos presos são jovens pobres, negros ou mulatos. $60 \%$ das mulheres encarceradas no Brasil são acusadas pelo delito de tráfico (BOITEUX, 2015, p. 142 e 144).

Colocando todas essas leituras em perspectiva, caberia questionar de que maneira a expansão e a globalização de um estado penal militarista acompanhou a aplicação de medidas de austeridade neoliberal ou a própria restruturação do Estado moderno (soberano sobre seu território e população) e como instituições militares e policiais foram redimensionadas dentro das fronteiras daqueles Estados que enfrentam o tráfico de drogas como ameaça (doméstica 
e global), autorizando um controle cada vez mais repressivo sobre grupos historicamente excluídos. No caso do Rio de Janeiro, para além da restruturação do Estado através da militarização da segurança pública em função da política (internacional) antidrogas, poderíamos dizer que ocorre a criminalização da pobreza e a institucionalização do racismo. Nas palavras de Stavrianakis \& Selby (2013), seria a incorporação da lógica militar na sociedade, de modo a legitimar a lógica estatal e suas práticas de controle social e manutenção da ordem. Para Karam (2013), é a militarização ideológica da segurança pública.

Sobre a construção de um regime global de biopoder, Corva (2009) afirma:

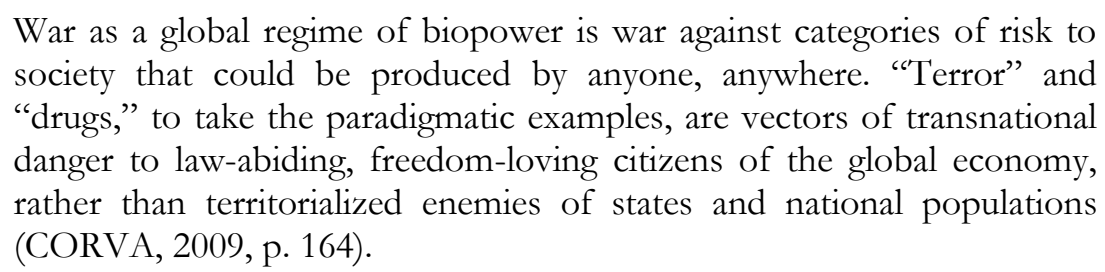

A noção de biopoder trabalhada neste artigo e expressa pelo autor citado se apoia na obra de Michel Foucault. Em Vigiar e Punir (1984), o autor analisa o processo de formação da sociedade disciplinar através das transformações da prática punitiva e o desenvolvimento de uma tecnologia do poder de punir que incide de forma precisa sobre o corpo: a biopolítica. É importante ressaltar que "este investimento político do corpo está ligado, segundo relações complexas e recíprocas, à sua utilização econômica" (FOUCAULT, 1984, p. 28). Uma das consequências do desenvolvimento deste biopoder, considera Foucault, é a crescente importância assumida pela norma, ou pelos mecanismos contínuos de regulação e correção, em conjunção com o sistema jurídico e da lei (FOUCAULT, 1988). Portanto, de um modo geral, na junção entre corpo e a população, assim como o sexo, a doença, a loucura, poderíamos dizer que a droga se tornou o alvo central de um "poder que se organiza em torno da gestão da vida” (FOUCAULT, 1988, p. 135).

O biopoder da guerra às drogas, segundo Corva (2009), baseia-se em dois princípios. Primeiramente, o de que "drogas" são uma ameaça global à segurança de corpos normais, saudáveis e economicamente produtivos. Em segundo lugar, o de que essa ameaça é tão massiva que as funções policiais relacionadas às atividades antidrogas deveriam se aproximar mais da guerra - contra "inimigos", não cidadãos, com alcance transnacional. Assim, podemos dizer que as leis que incidem sobre drogas, a proibição, são mecanismos determinantes para a realização de um poder de punir, para o controle social, para o encarceramento em massa de um grupo social especifico, visíveis na cidade do Rio de Janeiro. Considerando que a proibição seletiva de drogas autoriza uma vigilância repressiva e práticas 
punitivas rigorosas sobre aqueles corpos considerados criminosos, poderíamos incluir a política proibicionista de drogas dentro de um quadro mais geral de desenvolvimento do que Foucault chamou biopolítica. Nas palavras de Rodrigues:

\begin{abstract}
Somente com a proibição total de um conjunto de drogas psicoativas é que a questão sanitária e de saúde pública se converteu, também, em problema de segurança pública, amplamente lastreado nos juízos morais e racistas que demonizavam essas substâncias, quem as usava e as negociava. Desse modo, o controle de drogas, pautado pelo proibicionismo, poderia ser considerado uma potente tática biopolítica, pois, sincronicamente, permitiu a intervenção sobre hábitos individuais (uso de drogas para fins recreativos ou medicinais) - sob a justificativa de melhorar a vida individual e coletiva - e abriu espaço para a perseguição e apresamento de grandes contingentes de indivíduos tidos como perigosos à ordem social e que pertenciam, precisamente, às camadas mais pobres e numerosas dos centros urbanos que tanto preocupavam e mobilizavam - desde finais do século XVIII na Europa e a partir do final do século XIX nas Américas as classes governantes.(RODRIGUES, 2012, p. 13-14).
\end{abstract}

Internacionalmente, as ameaças, socialmente construídas, são identificadas com determinados países "problemas”, informada pela divisão geográfica, arbitrária, entre países "produtores" e "consumidores" de drogas ilícitas. O Plano Colômbia é o grande exemplo de militarização da agenda (bio) política antidrogas na América Latina. No entanto, essa divisão arbitrária do discurso geopolítico autoriza a militarização da política de segurança antidrogas também no Rio de Janeiro e em diversos centros urbanos do continente, marcando uma cartografia também dentro das cidades entre regiões e bairros abastados - e considerados os polos primários de consumo - e as favelas, onde o tráfico de drogas estaria primariamente abrigado (narrativa que apaga os crimes de colarinho branco que integram a própria cadeia produtiva do comércio internacional de drogas ilícitas).

O grande paradoxo é que os territórios, a soberania, a ordem e o controle são constantemente violados pelo comércio ilegal de drogas e pelos fluxos transnacionais (RODRIGUES, 2012). Como Rodrigues (2012, p. 33) afirma, o narcotráfico se constitui, em parte, de "empresas ilícitas transterritoriais, pois têm, simultaneamente bases e atuação locais (produção e comercialização) e trânsito transnacional, ultrapassando fronteiras políticas para sua realização como negócio". Casos de corrupção envolvendo instituições públicas e agentes de segurança no combate ostensivo às drogas também são regularmente denunciados pelos meios de comunicação. Nesse sentido, Corva (2009) é enfático:

Drug war discourses produce locally acceptable truths connecting real social disorder to fetishized illicit commodities rather than to local and 
global political and economic inequalities. This normalization has legitimated the expansion of the coercive capacity of states and illicit economic actors (CORVA, 2009, p. 171).

Nesse sentido, concretiza-se a ocupação militar das favelas, tidas como "território inimigo", com o objetivo de "libertá-las" do domínio de "traficantes de drogas" (KARAM, 2013). Com efeito, da proibição nasce o tráfico. E com a proibição, autoriza-se a militarização das atividades policiais, seja no Rio de Janeiro, no Brasil, ou em outros países. Como lembrado por Thiago Rodrigues (2012), "não foi a primeira vez que as Forças Armadas atuaram na segurança pública do Rio de Janeiro, visando à contenção ou vigilância sobre as favelas e seus moradores. [...] Tampouco foi a primeira vez que a sociedade aplaudiu essa forma de atuação” (RODRIGUES, 2012, p. 32). Ainda nas palavras do autor:

O catastrofismo dessa avaliação tem repercussões mais diretas, no entanto, em sociedades, como as latino-americanas, em que as Forças Armadas tiveram, historicamente, um papel de pacificação de revoltas e de conquista interna, além de inúmeras intervenções na vida política desses países, redundando em regimes autoritários. Desde os processos de independência nacional no século XIX, os militares latino-americanos foram frequentemente acionados para enfrentar inimigos internos, fossem populações autóctones, subversivos urbanos ou rurais, guerrilheiros ou sublevados. Foram poucas as guerras interestatais entre latino-americanos desde então; e menor ainda o engajamento de suas Forças Armadas em guerras interestatais extracontinentais. $\mathrm{O}$ uso de Forças Armadas contra próprios concidadãos parece ter sido, então, uma constante na história latino-americana, e a adoção entre nós da militarização do combate ao narcotráfico talvez possa ser compreendida como um redimensionamento contemporâneo desse processo, especialmente quando se nota que tal politica permanece voltada à repressão seletiva de grupos sociais historicamente visados pelas taticas de controle social (RODRIGUES, 2012, p. 34).

Sendo assim, os debates sobre "militarização" e "guerra às drogas" se relacionam na medida em que há uma confusão entre as funções da polícia e das Forças Armadas; em que se intensifica a militarização da função policial, legitimada pelo discurso proibicionista da política internacional e pelo desejo por ordem e controle; e pela expansão da punição como prática política de inclusão e exclusão. Portanto, para além de debater o futuro das Forças Armadas em regimes recém-democráticos ou as complexidades do comércio ilegal de drogas, precisamos abordar a militarização da função policial no contexto urbano de "guerra às drogas" e de globalização da guerra como biopoder, tendo como pano de fundo a governança econômico-política neoliberal e a política internacional antidrogas. 


\section{CONSIDERAÇÕES FINAIS}

Discussões sobre a militarização da segurança pública ganham fôlego no Brasil nos últimos anos. Por um lado, tramita no Senado Federal a Proposta de Emenda à Constituição (PEC) 51/2013, que tem como objetivo "reestruturar o modelo de segurança pública a partir da desmilitarização do modelo policial” (KARAM, 2013, p. 1). Por outro, a sociedade civil organizada avança pautas relacionadas à letalidade policial derivada do modelo militarizado de segurança pública, como no caso das recentes ações da Anistia Internacional Brasil sobre o extermínio da juventude negra no país e em relação a denúncias de execuções extrajudiciais cometidas pela Polícia Militar do Estado do Rio de Janeiro. De certa forma, são expressões de que a opinião pública está debatendo questões relacionadas à violência e à insegurança causadas, entre outros fatores, pela acentuada militarização das polícias, pelo redimensionamento da função das Forças Armadas e, de forma indireta, pela própria "guerra às drogas".

$\mathrm{Na}$ América Latina e internacionalmente, o debate sobre estratégias antidrogas se mostra mais acentuado e explícito. Organizações regionais como a Organização dos Estados Americanos (OEA) e a União das Nações Sul-Americanas (UNASUL) começam a incorporar discussão sobre possibilidades de mudança no paradigma militarizado promovido pelo regime internacional de drogas, seguindo tendência individual de distintos países latinoamericanos como Uruguai, Jamaica, Chile e Costa Rica. No plano internacional, caminha-se para a Sessão Especial da Assembleia Geral das Nações Unidas (UNGASS) de 2016, a primeira a apresentar chances reais de testemunhar alguma transformação mais profundas nas políticas globais sobre drogas ilícitas. No Brasil ou no mundo, essas mobilizações deixam claro que há posições divergentes sobre os rumos das políticas militarizadas de segurança pública, em específico quando associadas a um paradigma global de proibição de determinadas substâncias psicoativas.

O presente artigo é fruto dessas mobilizações e pretende, ao mesmo tempo, contribuir para o debate ao trazer o argumento de que, no Brasil, a militarização da segurança pública e a "guerra às drogas" se reconfiguram no contexto pós-ditadura, em que se construiu a (in)segurança doméstica atrelada a um imaginário de "inimigo" interno que perdura até os dias atuais. Nesse sentido, responde a provocações sobre militarismo, militarização, "guerra às drogas" e segurança pública feitas dentro e fora da academia, por ativistas como Karam (2013) ou por pesquisadores como Corva (2009) e Rodrigues (2012). As políticas 
internacionais de controle de drogas ilícitas, para além de promover uma (bio) política global de segurança capitaneada pelos Estados Unidos, legitimam o uso da violência e os mecanismos de controle social em âmbito doméstico que haviam se estruturado ainda durante o período autoritário brasileiro. Nesse contexto, a mobilização de forças de segurança nas fronteiras, nas periferias, nos territórios urbanos é uma afirmação da soberania do Estado, do desejo por ordem e controle que, na América Latina pós-redemocratização, encontra solo fértil. Os grandes centros urbanos da América Latina e, em específico, a cidade do Rio de Janeiro nos servem volumosos exemplos dessas práticas.

\section{REFERÊNCIAS}

BOITEUX, L. 2015. El antimodelo brasileño, prohibicionismo, encarcelamiento y selectividad penal frente al tráfico de drogas. Revista Nueva Sociedad, Buenos Aires, n. 255, p. 132-144.

BOWMAN, K. M. 2004. Militarization, Democracy, and Development: The Perils of Praetorianism in Latin America. Pensilvânia: The Pennsylvania University Press.

CARVALHO, J. M. 1999. Vargas e os Militares. In: PANDOLFI, D. (Org.). Repensando o Estado Novo. Rio de Janeiro: Fundação Getúlio Vargas.

CORVA, D. 2009. Biopower and the Militarization of the Police Function. ACME: An International E-Journal for Critical Geographies, British Columbia, v. 8, n. 2, p. 161-175.

COUTO, R. C. 1998. História Indiscreta da Ditadura e da Abertura. Rio de Janeiro: Record.

DEPEN - Departamento Penitenciário Nacional. 2014. Levantamento Nacional de Informações Penitenciárias. Disponível em: http://www.justica.gov.br/noticias/mj-divulgara-novorelatorio-do-infopen-nesta-terca-feira/relatorio-depen-versao-web.pdf. [02/08/2015].

DIAMOND, L.; HARTLYN, J.; LINZ, J. J.; LIPSET, S. M. 1999. Democracy in Developing Countries: Latin America. Boulder, Co: Lynne Rienner.

FIERKE, K. M. 2007. Critical Approaches to International Security. Londres: Polity Press.

FOUCAULT, M. 1984. Vigiar e Punir: Nascimento da Prisão. $3^{a}$ ed., Petrópolis: Vozes. 1988. História da sexualidade I: A Vontade de Saber. Rio de Janeiro:

Edições Graal.

HUYSMANS, J. 2006. The Politics of Insecurity: Fear, migration and asylum in the EU. Londres: Routledge.

JABRI, V. 2007. War and Transformation of Global Politics. Londres: Palgrave Macmillan.

KARAM, M. L. 2013. Sem o fim da "Guerra às drogas não haverá desmilitarização. Disponível em: http://www.leapbrasil.com.br/media/uploads/texto/88_Desmilitarização\%20\%20ALERJ.pdf?1391624538. [29/11/15]. 
PINHEIRO, P. S. 1982. Polícia e Crise Política: o caso das polícias militares. In: PAOLI, M. C. et al. A Violência Brasileira. São Paulo: Editora Brasiliense.

RIBEIRO, L.; MONTANDON, A. M. 2014. O que os policiais querem dizer com 'policiamento comunitário': uma análise dos discursos dos oficiais da PMERJ. DILEMAS: Revista de Estudos de Conflitos e Controle Social, Rio de Janeiro, v. 7, n. 2, 233-260, abr-jun.

RODRIGUES, T. 2012. Narcotráfico e militarização nas Américas: vício de guerra. Contexto Internacional, Rio de Janeiro, v. 34, n. 1, p. 9-41.

SOUZA, L. A. F. 2015. Dispositivo militarizado da segurança pública: tendências recentes e problemas no Brasil. Revista Sociedade e Estado, Brasília, v. 30, n. 1, p. 207-223.

STAVRIANAKIS, A.; SELBY, J. 2013. Militarism and International Relations in the Twenty-First Century. In: STAVRIANAKIS, A.; SELBY, J. (Eds.). Militarism and International Relations. Londres: Routledge.

STEPAN, A. 1988. Rethinking Military Politics: Brazil and the Southern Cone. Nova Jersey: Princeton University Press.

ZAVERUCHA, J. 2000. Fragile Democracy and the Militarization of Public Safety in Brazil. Latin American Perspectives, Londres, v. 27, n. 3, p. 8-31.

. 2001a. Militares e participação política no Brasil do final do séc. XX e início do séc. XXI. Revista USP, São Paulo, n. 49, p. 30-39.

. 2001b. Poder Militar: entre o autoritarismo e a democracia. São Paulo em Perspectiva, São Paulo, v. 15, n. 4, p. 76-83.

- 2005. Forças Armadas e polícia: entre o autoritarismo e a democracia, 1999-2002. Rio de Janeiro: Record. 2008. La militarización de la seguridad pública en Brasil. Revista Nueva Sociedad, Buenos Aires, n. 213, p. 128-146. 